\title{
Alcance de la S.A.S. en el derecho societario a la luz del principio de la libertad contractual
}

\author{
Scope of the S.A.S in the corporate right in the light of the principle of contractual liberty \\ Escopo do S.A.S. Na lei corporativa à luz do princípio da liberdade contratual
}

DOI: https://doi.org/10.21803/penamer.13.26.423

María Isabel Ortiz Cano https://orcid.org/0000-0002-0326-3610.

\section{¿Cómo citar este artículo?}

Ortiz, M. (2020). Alcance de la S.A.S. en el derecho societario a la luz del principio de la libertad contractual. Pensamiento Americano, 13(26), 93 112. DOI: https://doi.org/10.21803/penamer.13.26.423

\section{Resumen}

Este artículo analiza los incentivos y obstáculos jurídicos contenidos en la Ley 1258 de 2008 por la cual se crea en el ordenamiento jurídico la S.A.S., ley en la cual la mayoría de sus disposiciones son supletivas y una mínima cantidad son imperativas. Para ello se contrasta la regulación de este tipo societario con los otros vehículos societarios del Código de Comercio aún vigentes, teniendo como eje el principio de la libertad contractual y su desarrollo histórico en el derecho societario. Adicionalmente, el artículo mide los alcances de la S.A.S. en la legislación colombiana con un poco más de una década de vigencia.

Palabras clave: Libertad Contractual, Norma Imperativa, Norma Supletiva, Sociedades Del Código De Comercio, Sociedad Por Acciones Simplificada.

\begin{abstract}
This article analyzes the incentives and legal obstacles content by the Law 1258 of 2008 by which it is created in the legal system the S.A.S, law in which most of its provisions are supplementary and a minimum amount is mandatory. For this, the regulation of this type of scope is contrasted with the other company vehicles of the Commercial Code that are still valid, having as its axis the principle of contractual liberty and its historical development in corporate rights. Additionally, the article measures the scopes of the S.A.S in Colombia's legislation with a little more of a decade validity.

Keywords: Contractual Liberty, Mandatory Rule, Supplementary Rule, Commercial Code Corporations, Simplified Joint Stock Company.
\end{abstract}




\section{Resumo}

Este artigo analisa os incentivos e entraves legais contidos na Lei 1.258 de 2008 pela qual o S.A.S. é criado no ordenamento jurídico, lei em que grande parte de suas disposições são complementares e um valor mínimo obrigatório. Para tal, a regulamentação deste tipo de sociedade é contraposta aos demais veículos empresariais do Código Comercial que ainda se encontram em vigor, tendo como eixo o princípio da liberdade contratual e a sua evolução histórica no direito das sociedades. Além disso, o artigo mede o escopo do S.A.S. na legislação colombiana com pouco mais de uma década de vigência.

Palavras chave: Liberdade De Contrato, Regra Obrigatória, Regra Complementar, Sociedades Anônimas, Sociedade Anônima Simplificada.

\section{Perfiles}

Especialista en Derecho Comercial y Magíster en Derecho de la Universidad Pontificia Bolivariana (Medellín, Colombia). Docente interna en la Universidad Pontificia Bolivariana (Medellín, Colombia). Correo: mariaisabel.ortiz@upb.edu.co
María Isabel Ortiz Cano Abogada 


\section{Introducción}

La Sociedad por Acciones Simplificada "S.A.S." fue introducida como tipo societario en el ordenamiento jurídico colombiano a partir de la Ley 1258 del 5 de diciembre de 2008. Desde esa fecha y por más de una década, la S.A.S. ha conseguido ser el tipo societario más constituido en Colombia, dejando a los tipos societarios tradicionales regulados en el Código de Comercio “C.Co.” casi obsoletos.

Antes de la entrada en vigencia de la Ley 1258 de 2008, existían en Colombia alrededor de 658.793 sociedades registradas, lógicamente, para ese momento estas sociedades tenían como forma aquellos tipos regulados en el C.Co. donde predominan las restricciones y costos de transacción, o eran empresas unipersonales, de acuerdo con la Ley 1014 de 2006 (Confederación de Cámaras de Comercio, 2007). Con la S.A.S. esas limitaciones se minimizaron, facilitando la creación y formalización de empresas de la mano de incentivos tributarios y de crédito para los nuevos empresarios, tanto es así, que la S.A.S. se convirtió en el modelo societario preferido al momento de constituir una persona jurídica.

De hecho, se ha dicho que de cada 100 nuevas sociedades que se constituyen en Colombia, 98 son S.A.S. (Reyes Villamizar, 2018, p. 384). De un total de 456.459 sociedades inscritas a fecha de corte de agosto de $2019,383.920$ son S.A.S. $(84,108 \%)$ y 72.539 están organizadas en otras formas societarias o empresariales, así: 34 en sociedad colectiva (0,007\%), 7.322 en sociedad en comandita simple "S. en C." (1,604\%), 1.699 en sociedad en comandita por acciones "S.C.A." (0,372\%), 41.525 en sociedad de responsabilidad limitada "Ltda." (9,09\%), 12.340 en sociedad anónima "S.A." (2,703\%), 6.226 empresas unipersonales "E.U." (1,364\%), 1.759 sociedades extranjeras (0,385\%), 750 empresas asociativas de trabajo "E.A.T." (0,164\%), 12 en sociedad agraria de transformación "S.A.T." (0,003\%), 10 empresas industriales y comercial del Estado "E.I.C.E." (0,002\%) y 862 en otras formas de sociedad (0,189\%) (Confederación de Cámaras de Comercio, 2019); también se señala que 211.953 so- ciedades constituidas antes de la Ley 1258 de 2008 $(32,17 \%)$ fueron disueltas, bien sea porque se fusionaron o se liquidaron voluntariamente.

El auge alcanzado por la S.A.S. en Colombia tiene fundamento en el hecho de considerar la idea de modernizar el sistema societario mediante la implementación de un nuevo tipo capaz de minimizar las normas de carácter imperativo, es decir, aquellas de obligatorio cumplimiento que en caso de no ser atendidas darían lugar a la inexistencia del acto jurídico. Así pues, y a manera de ejemplo, en la S.A.S. se revalúan los requisitos de existencia del contrato de sociedad con relación a la pluralidad de socios, permitiendo que puede ser constituida por un único accionista o disminuyendo los costos de transacción, haciendo más fácil, accesible y económica la formalización de la empresa. La S.A.S. además faculta para que sean los mismos accionistas quienes formulen las reglas que gobiernen a su organización, de acuerdo con las necesidades internas, alejándose de la propuesta normativa contenida en las disposiciones supletivas de la Ley 1258 de 2008.

Dicha modernización del derecho societario es resultado de la evolución del principio de la libertad contractual que opera como fuente del Derecho por la cual "una vez que los individuos deciden contractar, pueden crear los efectos que les parezca, con plena libertad, teniendo como únicas restricciones las del orden público y las buenas costumbres" (Arrubla Paucar, 1997, p. 42); principio que cobra mayor importancia para el desarrollo del comercio al pretender que el tráfico mercantil se dé de manera más ágil y competitiva. Estos avances se observan en el contenido del Libro II del C.Co. que regula los tipos societarios tradicionales, pasando por la Ley 222 de 1995, la Ley 1014 de 2006 hasta llegar a la Ley 1258 de 2008.

Para el desarrollo del texto, se partirá de la noción de sociedad, la cual refiere a que ésta es un acto contractual "en el que dos o más personas se obligan a hacer un aporte en dinero o en trabajo o en otros bienes apreciables en dinero, con el fin de repartirse las utilidades obtenidas en la empresa o activi- 
dad social” (Peña Nossa, 2017, p. 22), concepto que también se aplica para la S.A.S. cuando proviene de la voluntad de una pluralidad de sujetos. Del mismo modo, se analizará las disposiciones normativas de la Ley 1258 de 2008, señalando los incentivos jurídicos que la ley consagra para las S.A.S. relativos a la constitución, capital y acciones, organización administrativa y reuniones, supresión de restricciones, disolución y liquidación, reorganización y reformas societaria, contrastándolos con la normatividad aplicable para los tipos societarios del C. Co.

Este texto se aborda en una metodología cualitativa, a partir de la reflexión de las normas jurídicas y de la doctrina especializada en la materia, y se desarrolla en dos capítulos: el primero, resume el desarrollo de la libertad contractual en el derecho societario; el segundo, presenta un análisis comparativo de las normas supletivas e imperativas que regulan a la S.A.S. en contraste con las formas societarias del C.Co. Luego, se exponen las conclusiones.

Finalmente, este artículo de reflexión pretende definir cuáles son los incentivos jurídicos y eventuales obstáculos derivados de la existencia de un mayor margen de libertad contractual para las S.A.S., razones que hacen que los empresarios en Colombia prefieran a este tipo societario para desarrollar sus negocios.

\section{La libertad contractual y su papel en la evolu- ción del Derecho Societario}

La legislación civil colombiana, con fundamento en el artículo 1602 del Código Civil “C.C.” se acentúa en el principio de la libertad contractual como expresión de la autonomía de la voluntad, por el cual las persona son libres de celebrar o no un negocio jurídico de acuerdo con sus intereses e intenciones, los cuales generarán efectos que serán determinados por las partes, que de tratarse de contratos, consistirán en producir obligaciones, y que sólo estará limitado por el orden público y las buenas costumbres, de acuerdo con el artículo 16 ibidem.
De esta manera "la voluntad privada crea derecho por sí misma; es fuente de derecho por su propia fuerza y en consecuencia el contrato es una ley para los contratantes" (Arrubla Paucar, 1997, p. 42). Esta noción de libertad contractual, replicada en la legislación interna, tiene su origen en la filosofía del Estado Liberal, el cual pretendía agilizar el comercio y la circulación económica.

En 1971 con la expedición del C.Co., la normatividad comercial se acoge a los postulados del C.C. sobre principios, formas de interpretación, efectos, formas de extinción, anulación o rescisión de las obligaciones y contratos, de conformidad con la remisión expresa que hace el artículo 822 del C.Co. De esta manera también se remite a la libertad contractual, principio que se consolidó aún más en la legislación comercial al considerar que los comerciantes podrían expresar su voluntad de celebrar negocios jurídicos por cualquier medio, salvo cuando expresamente, la misma ley determine unas solemnidades o requisitos para ciertos actos, de acuerdo con el artículo 824 del C.Co.

Sin embargo, para efectos societarios, esa libertad contractual se vio limitada, esto es, porque en el Libro II se reguló el contrato de sociedad, definiendo los tipos societarios, estableciendo sus requisitos para su existencia y constitución, y demás normas relativas al funcionamiento de la sociedad comercial, estableciendo para éstas normas en su mayoría de carácter imperativo, toda vez que la empresa que desarrolle una sociedad tiene una función social y económica, cuya dirección general está a cargo del Estado.

La norma imperativa, bastante recurrente en la regulación sobre los tipos societarios tradicionales, es aquella que "determina coactivamente el contenido del contrato a pesar de la voluntad de las partes" (Granados Aristizábal, 2013, p. 30), que para aquel momento histórico tenía como premisa la protección del interés general al considerar al "contrato social como un negocio de colaboración” (Arrubla Paucar, 1997, p. 52). 
Estas normas giran en torno a definir los elementos de la esencia del contrato de sociedad, tales como la pluralidad de socios, el aporte y la oportunidad para hacerlo de acuerdo con el tipo societario elegido (para la sociedad colectiva ver artículo 124; para S.C.A ver artículo 345; para la Ltda. ver artículo 354; para S.A. ver artículo 376), el objeto y la vocación de utilidad; además establecen para estas formas societarias que el elevar el contrato de sociedad a escritura pública es requisito para el nacimiento de la persona jurídica, acto que deberá inscribirse en el registro mercantil de acuerdo con los artículos 110 y 111 del .C.Co. Incluso, también se señalan disposiciones sobre el término de duración, administración, reservas, reuniones, exclusión, disolución, liquidación, en general, todas aquellas reglas relativas a la gestión de la sociedad

Teniendo como premisa que la sociedad, dentro del contexto del C.Co., es considerada como contrato, que implica un acuerdo de voluntades, se requiere para su existencia por lo mínimo dos o más voluntades que pretendan asociarse. El número mínimo o máximo de socios por cada tipo societario tradicional varía, y en caso de disminuirlo o excederse, dará lugar a que la sociedad se encuentre en estado de disolución, según el numeral tercero del artículo 218 del C.Co. Del mismo modo, se establece que el objeto social definirá la capacidad de la sociedad, por lo tanto, el objeto debe de ser determinado o determinable; misma suerte que corre el término de duración de la sociedad, el cual debe estar expresamente señalado en los estatutos de acuerdo con el artículo 99 y numerales 4 y 9 del artículo 110 del C.Co.

En las sociedades colectivas, se requiere la existencia de por lo mínimo dos socios, sin establecer número máximo; socios que responderán con su propio patrimonio de manera personal, solidaria, ilimitada y subsidiaria frente a las obligaciones contraídas por quien ostente la representación legal de la sociedad, que en caso de no ser delegada, estará a cargo de todos y cada uno de los socios, lo que implica que el objeto social que desarrolle la empresa debe de ser bastante conservador para disminuir riesgos para los asociados. En este tipo societario, los socios son titulares del interés social y para cederlo, se requiere de reforma estatutaria aprobada por la unanimidad de los socios, salvo que exista disposición en contrario en los estatutos, la cual también debe de elevarse a escritura pública y registrarse. Los socios serán titulares, cada uno, de un derecho al voto indistintamente de la clase y monto de su aporte, voto que también les faculta para vetar el ejercicio de operaciones sociales (artículos 294, 296, 310, 316 y 317 del C.Co.). Como puede observarse este tipo societario es el más restrictivo de la autonomía de la voluntad, y por lo tanto, el menos eficiente para el desarrollo de una empresa.

En las sociedades en comandita, que puede ser S. en C. o S.C.A. necesariamente deben de coexistir dos clases de socios, un gestor o socio industrial cuyo aporte es de hacer o administrar, y un comanditario o socio capitalista, cuyo aporte es de dar. Una misma persona puede realizar aportes de hacer y de dar, sin embargo, el gestor responde de manera personal, solidaria, ilimitada y principal, asumiendo todo el riesgo con su propio patrimonio, en cambio el comanditario responde hasta el valor de su aporte (artículos 323, 325 y 326 del C.Co.).

Cuando se trate de una S. en C., basta con que exista por lo menos un socio de cada tipo, siempre que exista pluralidad de sujetos, quienes cederán sus partes de interés o cuotas, respectivamente, o reformarán los estatutos sociales, mediante escritura pública, exigiéndose la unanimidad de los gestores y el voto favorable de los comanditarios, salvo en casos de cesión de cuotas del comanditario, en donde también se exigirá la unanimidad del resto de socios (artículos 338, 340 delC.Co.). En este tipo de sociedades se asumen pocos riesgos, pero por su estructura eran de la preferencia de sociedades de familia, sin embargo, la exigencia de la unanimidad desincentiva la inversión de terceros.

En la S.C.A., deberá de existir por lo menos un socio gestor y cinco comanditarios titulares de acciones. La cesión de partes de interés de los gestores se hará mediante escritura pública y aprobación unánime de todos los socios. Para las reformas estatutarias, que 
también requieren de la escritura pública, se debe contar con la unanimidad de los gestores y la mayoría de los comanditarios, salvo norma en contrario. Una S.C.A. es considerada una sociedad más competitiva en el mercado que las anteriores, que requiere de la capitalización de terceros mediante la adquisición de acciones, permitiendo que los gestores continúen con la administración. La transferencia de las acciones se hace mediante endoso y registro en el libro de accionistas, sin requerir de reforma estatutaria (artículos 347, 349 y 406 del C.Co.).

La Ltda, por su parte, estará conformada con mínimo 2 y máximo 25 socios, quienes responderán en principio sólo con el valor de su aporte, salvo en caso de obligaciones laborales (artículo 36 del Código Sustantivo del Trabajo “C.S.T.”) y tributarias (artículo 794 del Estatuto Tributario), en donde responderán con su propio patrimonio en proporción a su participación. En principio todos los socios tienen a cargo la administración de la sociedad, administración que puede ser delegada. Los socios podrán ceder sus cuotas sociales mediante reforma estatutaria por escritura pública con posterior inscripción, con la aprobación de un número plural de socios que representen por lo menos el $70 \%$ del total de las cuotas sociales (numeral quinto del artículo 358, artículos 360 y 366 del C.Co.). La Ltda. es una sociedad mediana, que incentiva la inversión, pero que se limita a un número de socios y a la forma en la que se ceden las cuotas sociales.

Finalmente, la S.A., exige tener como mínimo 5 socios, quienes al igual que los socios comanditarios en las S.C.A. tienen el beneficio de la separación patrimonial; la cesión de sus acciones no implica una reforma estatutaria, basta con la negociación del título valor (artículos 373, 374, 375 y 406 del C.Co.). Al no exponer el patrimonio personal de los accionistas, hace que este tipo societario haya prevalecido para realización de grandes negocios, incluso mediante la inscripción en la Bolsa de Valores.

Dentro del desarrollo legislativo en Colombia, aparece a mediados de la última década del Siglo XX la aplicación de la llamada teoría de descodi- ficación, la cual consiste en "la sustracción del código de su lugar central por la legislación especial. Se abandonó la unidad del sistema jurídico con la creación de una pluralidad de microsistemas, cada uno con principios y con lógicas propias" (Frontera, 2007, p. 227), que considera que, debido a los cambios de las instituciones sociales, los códigos se vuelven obsoletos e incompletos, que no alcanzan a regular las nuevas relaciones, por lo cual se expiden estatutos autónomos más específicos y sencillos que se encargan de integrar al ordenamiento jurídico. En materia societaria la descodificación puede evidenciarse con la promulgación de leyes como la Ley 222 de 1995, la Ley 1116 de 2006 y la Ley 1258 de 2008 (Villa Uribe, 2015, p. 6).

La Ley 222 de 1995 ha sido la norma que dio origen a la modernización del régimen societario en Colombia regulando la figura de la E.U. con responsabilidad limitada, que si bien no se considera sociedad, de acuerdo con la concepción tradicional de la misma por ser constituida por una única persona natural o jurídica, sí reviste una organización y regulación semejante, ya que "una vez inscrita en el registro mercantil, forma una persona jurídica, constituyendo de por sí un patrimonio autónomo y distinto al del empresario" (Macías Reyes, 2018, p. 9). También se destaca la aparición del objeto social indeterminado, el término indefinido de duración y la regulación de la desestimación de la personalidad jurídica, se regula la escisión, el derecho de retiro, los grupos empresariales y los acuerdos de sindicación de acciones.

Para el 2006 se expide la Ley 1014, también conocida como ley del emprendimiento empresarial, la cual admitió en el artículo 22 la creación de pequeñas empresas de naturaleza unipersonal, superando definitivamente el requisito de pluralidad de socios, tal como lo introdujo la Ley 222 , siempre que al momento de su constitución se cuente con diez o menos trabajadores o con activos inferiores a quinientos salarios mínimos legales mensuales vigentes. Sin embargo, esta disposición generó un gran debate en la doctrina, por considerar que las socie- 
dades unipersonales en Colombia "debían adoptar, y funcionar, al amparo de un tipo societario de los establecidos en el Código de Comercio" (Espinosa Quintero, 2011, p. 262). En el mismo año también se expide la Ley 1116 que establece el Régimen de Insolvencia Empresarial.

No obstante todo lo anterior, no es hasta el 5 de diciembre de 2008 cuando se expide la Ley 1258, por la cual se introduce en la legislación colombiana a la S.A.S., cuyo móvil, de acuerdo con el informe de ponencia legislativa es:

La tendencia actual apunta a simplificar la normatividad, en beneficio de un mayor campo de acción a la autonomía de la voluntad privada. Con ello se pretende asegurar la inclusión de la pequeña y mediana empresa en el sector formal de la economía, a través de la consolidación de estructuras societarias menos complejas y, por ende, sujetas a un menor rigorismo jurídico. (Congreso de la República, 2008, p. 4)

Así entonces, el legislador consideró que las normas que rigen a la S.A.S. pregonaría por un mayor ejercicio de la libertad contractual en el derecho societario, toda vez que en el contenido de la ley harían presencia en su mayoría normas de carácter supletivo, es decir, aquellas que "cuya aplicación no tiene cabida más que cuando no se ha dispuesto nada distinto por los sujetos negociales o ellos han guardado silencio frente a aspectos a que aquéllas se refieren" (Hinestrosa, 1969, p. 287); igualmente, para la S.A.S., se estaría disminuyendo también costos de transacción y requisitos para quienes decidieron optar por esta figura, asunto que será objeto de estudio en el siguiente acápite.

Análisis normativo de las S.A.S. en contraste con las formas societarias del C.Co.

Partiendo de un análisis del contenido de la Ley
1258 de 2008, se identificarán los incentivos jurídicos de la S.A.S. relativas a la constitución, capital y acciones, organización administrativa y reuniones, supresión de restricciones, disolución y liquidación, reorganización y reformas societaria, distinguiendo entre aquellas de carácter imperativa de las supletivas.

\section{Constitución de la S.A.S.}

En consonancia con las nuevas corrientes de suprimir trámites para la constitución y funcionamiento de las sociedades comerciales, que garanticen niveles de eficiencia en términos de tiempo y dinero, se permite que la S.A.S. tenga uno o varios socios, sin existir un límite numérico de accionistas que pueden ser personas naturales o jurídicas. Con este alcance, se entiende ahora a la sociedad como un mejor instrumento del desarrollo económico, es decir, "una unidad económica productiva, un sujeto de derecho que actúa en el tráfico mercantil, con independencia de cuántos son sus socios" (Velásquez Restrepo, 2017, p. 4).

La voluntad de los partícipes para la conformación de la nueva sociedad puede hacerse mediante documento privado con reconocimiento de firma y contenido de parte de los socios o apoderado ante notario o funcionario de la Cámara de Comercio; o escritura pública, por simple voluntad de las partes o cuando en los aportes haya bienes susceptibles de registro. El instrumento de constitución deberá ser inscrito en el registro mercantil. Esta novedad que trae la ley de poder inscribir a la sociedad mediante documento privado, ha reducido notoriamente los costos de los trámites societariosl, ya que los gastos notariales, además de ser una expensa sin un beneficio asociado para la nueva compañía, eran "en el pasado una de las razones que detenían a las micro y pequeñas empresas para formalizar su negocio, pero ahora es un claro incentivo a la creación de empresa y la efectiva consolidación de patrimonio en una persona jurídica” (Betancourt, Gómez, López, Pamplona \& Beltrán, 2013, p. 216).

1 Cuando se trata de constitución o reformas estatutarias por escritura pública, el valor a pagar se determina anualmente por la Superintendencia de Notariado y Registro, de acuerdo con tipo de acto, valor del capital, otorgantes y hojas. Si es un documento privado para el caso de la S.A.S. presentando ante notaría, se deberá realizar reconocimiento de firma y contenido del documento, y el valor se calculará según el número de otorgantes y hojas. Ver, por ejemplo, Superintendencia de Notariado y Registro. Resolución O1299 del 11 de febrero de 2020. En Cámara de Comercio, para ambos casos, se deben de cancelar otros rubros para el respectivo registro del acto. Particularmente, en el caso de las S.A.S. las Cámaras de Comercio han implementado mecanismos para el registro por medios virtuales.

Pensamiento Americano Vol. 13 - No. 26 - p.p. 93-112 • 2020 • Julio-Diciembre • Corporación Universitaria Americana • Barranquilla, Colombia • ISSN: 2027-2448 http://publicaciones.americana.edu.co/index.php/pensamientoamericano/index 
Sólo con el registro del documento privado o de la escritura pública en la Cámara de Comercio del domicilio de la sociedad, esta nacerá a la vida jurídica, y con ello, por corresponder a una sociedad por acciones, en cabeza de los socios se constituirá el beneficio separación patrimonial, por el cual, éstos únicamente responderán hasta el monto de los aportes, incluso, cuando se trate de obligaciones tributarias y laborales, salvo casos desestimación de la personalidad jurídica, esto es, cuando la sociedad es utilizada como mecanismo para defraudar a trabajadores, acreedores y al Estado, de conformidad con el artículo 42 de la Ley 1258. Así las cosas, en virtud del beneficio de separación patrimonial, ante la deuda personal de un accionista, la sociedad no está llamada a cumplir con su obligación, y respecto de los acreedores de la sociedad, el pago se garantiza con el patrimonio de la compañía. Al respecto la jurisprudencia ha establecido:

"El legislador quiso dotar a la empresa y a la economía de una herramienta más ágil y flexible en cuanto a su constitución, composición y funcionamiento en comparación de las otras formas de asociación, con el fin de modernizar el derecho societario, hacer la industria más competente e incentivar el desarrollo del país. La separación del patrimonio de la sociedad y de los accionistas obedece a un propósito constitucional consistente en permitir el flujo de capital, la inversión y la estimulación del desarrollo empresarial del país, de conformidad con el artículo $333 \mathrm{CP}$." (Corte Constitucional, Sentencia C-090, 2014, pág. 1).

Por otro lado, dentro de los estatutos sociales también es posible que los constituyentes definan el término de la sociedad y las actividades que compongan el objeto social; en caso de silencio, por tratarse de normas supletivas, el término se entenderá como indefinido y el objeto social indeterminado, por lo cual, la sociedad podrá realizar cualquier actividad siempre y cuando sea lícita. "La presencia de la SIC supone la existencia de un ente especializado en la materia a nivel central, que se encarga del control y vigilancia de los derechos de los consumidores". (Sayas Contreras, 2016).
Definir en los estatutos la actividad económica a realizar por la empresa corresponde a una decisión de los accionistas, bien por desconfianza en los administradores o por considerar necesario especializar el objeto social, lo que implica que todo acto de la sociedad que se realice por fuera de su objeto es susceptible de ser declarado nulo, dando lugar a una inseguridad jurídica para los terceros contratantes. Ahora bien, en caso de que tal confianza exista o cuando los administradores son los propios accionistas, no tiene sentido limitar el objeto social a un listado taxativo de actividades. Además, en caso tal de que se restrinja el objeto social, implica que cuando se quiera incursionar en un nuevo negocio se deba realizar una reforma estatutaria, tal como se exige en las formas societarias del C.Co. Sobre estos aspectos objeto de la disposición de los accionistas se ha comentado:

En esa ideología se evidencia la libertad en cuanto a que este tipo societario es una sociedad de capitales y de naturaleza puramente comercial, independientemente de las actividades previstas en su objeto social, lo que denota simplemente en actividades lícitas sin especificación mayor, es decir, que pueden desarrollar cualquier actividad comercial, entonces el objeto social puede ser indeterminado, lo que la facultad para realizar cualquier actividad lícita, siempre y cuando sus actividades no se encuentren delimitadas en los estatutos...Junto con lo anterior se suma que el término de duración puede ser indeterminado, a diferencia de los demás modelos societarios que deben ter un término de duración definido. (Jaramillo Marín, 2014, p. 82).

\section{El capital y las acciones en la S.A.S.}

Con respecto a las reglas y sobre el capital y acciones, se demuestra aún más que el contenido de la S.A.S. goza de gran libertad contractual para quienes a ella pertenecen. Los accionistas tienen la posibilidad de pagar el capital suscrito dentro de los dos años siguientes a la fecha de constitución de la sociedad, término más amplio que el existente para otros tipos 
societarios, que facilita la financiación vía patrimonial, y que no es excesivo, toda vez que un término legal superior podría generar conductas oportunista por parte de los accionistas que han prometido realizar su aporte y que observan que en los primeros años de la compañía los resultados no son muy favorables. Sobre esta imposición cabe decirse que "no es posible dejar librado a la voluntad de los socios la fecha en que habrán de pagar sus aportes, teniendo en cuenta que es el capital de trabajo de la sociedad" (Velásquez Restrepo, 2017, p. 8). Sin embargo, la Ley 1258 no previó un mecanismo en caso de incumplimiento de este plazo, por lo cual, los socios podrán disponer una sanción y un procedimiento dentro de los estatutos, o de lo contrario, recurrir a lo establecido en el artículo 397 del C.Co.

En las sociedades tradicionales no era posible establecer montos máximos o mínimos de capital para asegurar el control de alguno o algunos de los asociados en la compañía, de manera directa o indirecta, es decir, reglas que permitirán definir “de modo anticipado y con carácter obligatorio, el grado de poder decisorio que cada persona o grupo ha de tener durante la vida de la sociedad" (Reyes Villamizar, 2018, p. 230); en cambio, de acuerdo con el segundo inciso del artículo 9 de la Ley 1258 sí se permite que los accionistas de una S.A.S. determinen en sus estatutos normas al respecto que señalan los límites o que clasifiquen las acciones con un porcentaje de votos para cada grupo y las respectivas consecuencias de su incumplimiento.

Del mismo modo, en caso en que una sociedad sea a su vez accionista de otra, en el artículo 16 se establece que podría estipularse como una obligación a cargo de la sociedad accionista, informar sobre las operaciones que impliquen un cambio de control. Así entonces, en caso tal de que los accionistas hayan determinado como perentorio el deber de informar el cambio de control de la sociedad, y fácticamente se haya cumplido con este supuesto sin haber sido comunicado, la ley estimó como sanción la facultad de que la asamblea apruebe la exclusión de la sociedad accionista y la reducción de hasta el $20 \%$ del re- embolso de la participación. Tanto la norma sobre montos de participación como cambio de control en sociedad accionista, tienen como finalidad evitar la burla al derecho de preferencia en la venta de acciones de una S.A.S. cuyos accionistas sean otras sociedades. "El conocido expediente de transferir las acciones de una sociedad accionista a un tercero constituye un mecanismo claramente violatorio del derecho de preferencia” (Reyes Villamizar, 2018, p. 232).

Como se ha venido advirtiendo, la S.A.S. parte de "la plena libertad de estipulación de los socios de configurar el capital social, sus acciones, como convengan...Habrá mínimos inderogables, pero también amplias permisividades que rompan incluso con la paridad del voto, la paridad de la distribución de beneficios" (Veiga-Copo, 2011, p. 383). Es por lo anterior que por decisión de los socios de una S.A.S. se permite emitir, acciones ordinarias, con dividendo preferencial y sin derecho al voto sin límite porcentual en el capital, de dividendo fijo anual, de voto múltiple, de clase y de pago, lo cual es considerado como un gran avance de las S.A.S. respecto de los demás tipos societarios.

Inicialmente, las sociedades por acciones del C.Co. podían emitir acciones ordinarias y privilegiadas, las cuales otorgan a su titular derechos políticos y económicos contenidos en los artículos 379 y 381, respectivamente. Posteriormente, con la intención de atraer nuevos inversionistas, el artículo 61 de la Ley 222 de 1995 otorga la posibilidad a las sociedades por acciones de emitir acciones con dividendo preferencial y sin derecho al voto, las cuales no podrán representar más del $50 \%$ del capital suscrito.

Todo esto conlleva a decir que, a través de las S.A.S., han incursionado en el derecho societario las acciones con dividendo fijo y anual, pues "crean un incentivo para los inversionistas semejante al que se obtiene al adquirir títulos de renta fija” (Reyes Villamizar, 2018, p. 98), en las cuales, se puede limitar las ganancias a repartir de cada acción, pero a diferencia de las anteriores, se conserva el derecho al voto; $y$ las acciones de pago, que permiten la remuneración 
del salario de especie de los administradores según los límites contemplados en el C.S.T., como forma de incentivo a la participación del empleado, honrando los servicios prestados a la compañía. Estas acciones de pago pueden ser ordinarias o de cualquier otro tipo, pero su característica diferenciadora es el móvil para emitirlas, que en este caso en un trabajo o la prestación de un servicio.

Incluso, es viable que se estipulen en las S.A.S. derechos políticos múltiples para algunas acciones con el fin de definir la capacidad de control político de un accionista, es decir, puede garantizarse que con la voluntad de los titulares de las acciones con voto múltiple es suficiente para tomar decisiones de trascendencia de la sociedad. El voto múltiple es una herramienta utilizada en las sociedades de familia bajo la forma societaria S.A.S., en la cual, los padres conservan el poder decisorio sin necesidad de ostentar la mayoría de las acciones, lo que ha generado un desplome en la constitución de nuevas sociedades en comandita y la transformación de la mayoría de las ya existentes a S.A.S. (Mendoza, 2019). Sobre el voto múltiple se ha expresado:

"La Ley 1258, a diferencia de otras legislaciones foráneas, no limita el número de votos que se puede otorgar por cada acción, lo que implica que en cada caso les corresponderá a los interesados definir estatutariamente las condiciones y características del voto múltiple, cuando quiera que pretenda cogerse esta posibilidad que brinda la ley. A título ilustrativo es del caso indicar que el voto múltiple se justifica cuando se pretenden asegurar con una mínima, menor o paritaria inversión, el control en la toma de las decisiones o para evitar modificaciones en las mayorías decisorias en los sucesivos incrementos de capital." (Superintendencia de Sociedades, 2009, p. 2, 3).

Así mismo, en virtud del derecho de preferencia por el cual, el oferente de las acciones puede exigir un valor mayor sobre ellas o por el carácter intuito personae que pueden acoger algunas S.A.S., existe la posibilidad de que los socios restrinjan la enajenación de acciones hasta por un término de diez años a partir de su emisión, de todas o algunas de las acciones, estableciendo la ineficacia como sanción en caso de celebrarse una negociación irrumpiendo a esta regla. Este período podrá ser prorrogado por una sola vez y por el mismo término en caso en que confluya el consentimiento de todos y de cada uno de los accionistas de conformidad con el artículo 13 de la Ley 1258. De igual manera, en virtud del artículo 14 ibidem, los socios pueden establecer que, para cualquier enajenación de acciones, se requiera de la aprobación de la asamblea.

\section{Organización administrativa y reuniones en la} S.A.S.

De acuerdo con la organización de la sociedad, los accionistas podrán definir con autonomía su estructura orgánica y funcionamiento, sin embargo, se establece como de obligatorio cumplimiento que en una S.A.S. exista una asamblea general de accionistas como el máximo órgano de una sociedad y un representante legal. En caso de ser una sociedad conformada por un único socio, en cabeza de éste estará el ejercicio de las funciones encomendadas en el artículo 420 del C.Co. para la asamblea general de accionistas.

El representante legal estará a cargo de la administración de la sociedad y podrá ser elegido hasta por un término indefinido; inclusive, nada obsta que el cargo se ejecute por fuera del domicilio de la sociedad, teniendo en cuenta que la S.A.S. es un instrumento de inversión, en donde los administradores y accionistas pueden ser incluso extranjeros o tener domicilio por fuera del territorio nacional, lo cual les facilitaría para estar a cargo de su gestión sin delegar la representación legal. En principio, salvo disposición en contrario que limite sus facultades referentes al objeto o cuantía, el representante legal podrá celebrar y ejecutar todo tipo de actos jurídicos que se relacionen con el objeto social o actos de los cuales dependan la existencia y funcionamiento de la sociedad.

Sobre la realización de la asamblea de accionistas 
de una S.A.S., de acuerdo con la tendencia a flexibilizar los trámites societarios se ha quebrado el molde del C.Co., el cual, solamente permitía que las reuniones se realizarán en el domicilio social, so pena de que las decisiones que allí se tomen sean sancionadas con la ineficacia, salvo que se tratara de reuniones universales. Así entonces, las reuniones de la S.A.S. podrán hacerse en el domicilio de la sociedad cuando haya proximidad geográfica de los accionistas o por fuera, sin requerir un quórum universal; "de todas formas nada se opone a que los accionistas, voluntariamente pacten la prohibición de celebrar reuniones por fuera del domicilio social" (Velásquez Restrepo, 2017, p. 16).

Inclusive, para facilitar los procesos en la toma de decisiones, se permite el uso de mecanismos de comunicación simultánea, sucesiva o por medio escrito, tales como comunicación telefónica, teleconferencia, chat o fax, de cuyo uso debe de dejarse constancia, sin requerirse de la presencia de un delegado de la Superintendencia de Sociedades. Sobre estas reuniones no presenciales, la sociedad podrá establecer reglas internas para su funcionamiento, inclusive, podrá suprimir el requisito del quórum universal; en caso tal en que los accionistas guarden silencio en los estatutos respecto de este asunto, se aplicarán las normas contenidas en los artículos 19 a 21 de la Ley 222 de 1995, por los cuales se exigirá la totalidad de los socios en estas reuniones so pena de ineficacia de la decisión adoptada.

Para las convocatorias, la Ley 1258 en el artículo 20 establece como norma supletiva que, la asamblea será convocada por el representante legal, mediante comunicación escrita dirigida a cada accionista con una antelación mínima de cinco días hábiles, en donde se insertará el orden del día de la reunión; período en el que se ejercerá el derecho de inspección cuando la reunión trate de la aprobación de balances de fin de ejercicio y de operaciones como transformación, fusión y escisión.

Por ser una norma objeto de la voluntad de los accionistas, estos podrán establecer dentro de los es- tatutos una nueva disposición sobre convocatorias aplicables a su S.A.S., por lo cual podrán establecer otro medio de comunicación, autorizar a otras personas diferentes al representante legal para citar a reunión, por ejemplo, un número de socios, revisor fiscal o junta directiva, si cuentan con dichos funcionarios, y establecer un lapso mayor para el envío de la comunicación. Este término de cinco días resulta ser más corto en contraste con las reuniones de la S.A. en las cuales se exige que la convocatoria se haga con no menos de quince días, cuyo fundamento es la practicidad para desarrollar las asambleas, más aún cuando en algunas S.A.S. son pocos los accionistas y son ellos mismos quienes administran la sociedad. Un término corto como éste es útil para ahorrar el número de días necesarios para formalizar una decisión a través de una asamblea y cuando no es necesario un plazo mayor para que los accionistas se informen adecuadamente.

De existir cualquier vicio en la convocatoria, ya sea por la omisión de esta o su inadecuada formulación, es permitido que los socios renuncien a su derecho de ser convocados, e incluso, al derecho de inspección, siempre que la decisión que se tome en la asamblea no le cause algún perjuicio al accionista. Tal renuncia puede ser útil, por ejemplo, en las sociedades cerradas o de familia, donde es usual que los socios ocupen cargos de administración, garantizando de esta manera, que la decisión tenga efectos jurídicos y no sea sancionada con la ineficacia, consecuencia jurídica que suele ser la aplicable en las formas societarias que anteceden a las S.A.S. Dicha renuncia puede hacerse de manera escrita, antes, durante o posterior a la asamblea, o de forma tácita, asistiendo a la asamblea donde no fue citado sin expresar inconformidad por la convocatoria.

Bajo la regulación de la S.A.S., se hace un salto del requisito de pluralidad constante en las sociedades del C.Co., por el cual, para deliberar y decidir se requiere de varios socios, y es que se resalta que la nueva forma societaria puede existir aún con un único accionista. Norma que se aplaude toda vez que garantizar el número de socios para constituir 
y mantener una sociedad tradicional genera grandes costos de transacción, porque en la práctica "el formalismo y la severidad el sistema contractualista conduce con frecuencia a la constitución de sociedades de favor y a la constante simulación del negocio jurídico societario” (Reyes Villamizar, 2018, p. 92).

Además, en muchos casos el acto de constitución de los tipos de sociedades tradicionales se logra “obteniendo colaboración de ciertas personas que, aunque no deseen ser socios, acepten figurar como tales en los documentos sociales, quedando así satisfecha la inútil exigencia legal de la indicada pluralidad”. (Gaviria Gutiérrez, 2004, p. 37), en virtud del cual, un único asociado podría ser el titular mayoritario de las acciones, y los demás, simplemente están sometidos a su poder decisorio, sin tener una intervención alguna en la sociedad, porque son solamente socios para cumplir con la formalidad de la pluralidad. Por ejemplo, en la S.A. solían ser comunes casos en donde un accionista detentaba el máximo porcentaje permitido por la ley, 94,99\%, y otros cuatro accionistas, para cumplir con el mínimo de 5 asociados, tenían el restante 5,01\% de acuerdo con los artículos 374 y 457 del C.Co. Pero estos cuatro últimos accionistas lo eran solo de papel porque mediante un acuerdo informal, de dudosa legalidad, aceptaban ser propietarios "a nombre" o en interés del accionista mayoritario. La ley, pues, en vez de proteger a los accionistas antes propiciaba el fraude.

De tal manera, en principio, para todos o ciertos temas, las reuniones podrán realizarse con la presencia de una o varias personas que representan por lo menos la mitad más una de las acciones suscritas, y las decisiones se toman con la aprobación de la mayoría de las acciones presentes, atendiendo, además, a los derechos políticos otorgados a cada acción, según sea su tipo. Ello es así, porque la norma contenida en el artículo 22 de la Ley 1258 de 2008 es de carácter supletivo, lo que implica, que los socios, en el ejercicio de su libertad contractual, puedan establecer norma distinta, acordando un quórum superior, inclusive la unanimidad, para deliberar y decidir, y exigiendo la concurrencia de dos o más voluntades para la toma de decisiones, con el fin de restarle fuerza al poder del socio mayoritario, supuesto que dificultaría la toma de decisiones de trascendencia de la sociedad.

Con el fin de no verse frustrada una reunión por falta de quórum, el representante legal o quién esté facultado para convocar a la asamblea de acuerdo con los estatutos sociales, podrá indicar desde el primer aviso que, de no realizarse la reunión citada, se llevará a cabo una asamblea de segunda convocatoria, señalando fecha y hora de esta. La Ley 1258 en el parágrafo del artículo 20 expresamente advierte que la reunión de segunda convocatoria no podrá hacerse entre los diez días siguientes a la fecha prevista de la primera convocatoria ni treinta días posteriores.

La posibilidad de hacer esta segunda convocatoria desde la citación inicial es bastante conveniente en una S.A.S. porque junto con las normas comentadas anteriormente, procura que exista facilidad y agilidad para la toma de las decisiones de la sociedad, y en particular, porque garantiza que con el recibo de la convocatoria a la asamblea donde no hubo quórum, los accionistas quedan a priori notificados de la segunda fecha, con el consiguiente ahorro de tiempo que tan importante es para poder discutir una decisión en la asamblea respectiva de forma oportuna, y no cuando ya termina siendo inocua porque, verbigracia, la oportunidad de negocio expiró o lo propio sucedió con un término legal.

Además, la norma otorga un término prudente para mantener la continuidad temporal sobre los asuntos objeto de discusión y superar las dificultades que imposibilitaron a los ausentes a asistir a la primera reunión. Sin embargo, en caso reincidir en la falta de quórum en la reunión de segunda convocatoria, ello no será un obstáculo para deliberar y decidir, porque no se requerirá de pluralidad, “de modo que, si sólo asiste un accionista, deberá entenderse facultado para adoptar todas las decisiones que correspondan, a menos que, conforme a los estatutos, ellas requieran una mayoría calificada" (Reyes Villamizar, 2018, p. 243). 
Sobre la junta directiva en la S.A.S., ésta será un órgano discrecional de la administración, cuyas facultades, funcionamiento y elección se remitirá a lo que se señale en los estatutos de acuerdo con los postulados de la autonomía y libertad de los accionistas. "Su inclusión es perfectamente viable en este tipo de sociedad, aunque no es indispensable" (Reyes Villamizar, 2018, p. 257); este órgano se piensa para ejercer funciones de vigilancia y control sobre el representante legal y para fijar políticas administrativas. En particular, sobre el nombramiento, se estipulará en el contrato de sociedad si se hará mediante el uso del cociente electoral, el de mayorías o cualquier otro mecanismo adoptado por los socios, además del número de integrantes, quienes podrán tener a sus respectivos suplentes.

Esta regulación sobre la junta directiva en la S.A.S. aclara tota duda relativa a su obligatoriedad, creación, elección de sus miembros y funcionamiento; escenario que no es pacífico en la S.A. Ninguna norma del C.Co. que regule a la S.A. hace mención expresa a la obligatoriedad de este órgano, en estricto sentido, el artículo 434 del C.Co. se refiere a la manera en la que debe de funcionar la junta directiva en caso de que los accionistas opten por conformarla, lo que quiere decir que la junta directiva en una S.A. es un órgano facultativo, que puede ser o no conveniente, de acuerdo a cada caso particular (Gaviria Gutiérrez, 2004). Sin embargo, la Superintendencia de Sociedades y gran parte de la doctrina mantienen una posición formalista, generadora de burocracia y alejada de una interpretación conforme a una norma que es clara, que la junta directiva sí es un órgano obligatorio en una S.A. (Superintendencia de Sociedades, 2000). En todo caso, en una S.A., la junta directiva debe estar integrada con no menos de tres personas, cada uno con su propio suplente, designados por la asamblea de accionistas mediante el sistema de cociente electoral.

La junta directiva es un órgano útil en aquellas sociedades conformadas por una gran pluralidad de socios, donde el patrimonio es cuantioso, las actividades económicas son diversas por lo que la direc- ción del negocio es una gestión compleja, además, porque puede representar un margen de seguridad para el asociado que por cualquier motivo no puede intervenir en la administración social. Y, en general, tal junta directiva tiene sentido, así la sociedad no esté en un mercado público de valores, cuando hay una clara separación entre la propiedad (accionistas) y el control (administradores).

En sentido contrario, en las sociedades cerradas, al menos de tamaño pequeño o mediano, carece de trascendencia su incorporación, ya que las funciones de administración podrían ser perfectamente desplegadas por su representante legal, sin injerencia de miembros de la junta directiva, que de existir, no garantizan que realicen un control sobre la gestión del representante legal; por el contrario, su incorporación puede dar lugar a que la sociedad destine esfuerzos para cumplir con formalidades y requisitos costosos, propios de un sistema burócrata, donde la asignación inequitativa de honorarios es una modalidad para expropiar a los socios minoritarios. Adicionalmente, en caso tal de que los miembros de la junta no cumplan con las funciones a cargo, éstos asumen los riesgos de las sanciones legales aplicables.

Lo anterior ha sido objeto de análisis de la propia Superintendencia de Sociedades, la cual, en sentencia emitida en el proceso con radicado 201-01-276188, falló a favor de un socio minoritario quien demandó a dos socios que ostentaban la mayoría de las acciones suscritas en una S.A.S. por haber ejercido su derecho al voto de manera abusiva. En asamblea extraordinaria de accionistas, los accionistas mayoritarios delegaron a sus propios familiares como miembros de la junta directiva y fijaron para estos honorarios que contrastaban significativamente con las pocas labores realizadas por la junta directiva, según constó en actas. Esto fue una expropiación de flujos de caja que generó un grave perjuicio para el demandante al reducir considerablemente las utilidades a repartir. Probado el ejercicio abusivo del derecho al voto con el fin de expropiar a un accionista, los demandados fueron condenados a indemnizar los perjuicios ocasionados al accionista minoritario (Superintendencia de Sociedades, 2015). 
Supresión de restricciones en la S.A.S.

La Ley 1258 en su artículo 38 suprime para las S.A.S. unas restricciones contenidas en los artículos 155, 185, 202, 404, 435 y 454 en el C.Co. Estas disposiciones aún vigentes para las otras formas societarias exigen que, para el reparto de utilidades, el quórum decisorio es como mínimo el $78 \%$ de las acciones, cuotas o partes de interés presentes en la reunión, además que, en caso de no obtener esta mayoría y de existir pérdidas a enjugar, es decir, aquella que reduzcan el patrimonio por debajo del umbral, como mínimo se debe repartir el 50\% de las utilidades líquidas de la empresa y el 70\% de las utilidades si la sociedad tiene utilidades que exceden el $100 \%$ del capital suscrito (artículos 155 y 454); los representantes legales, administradores y empleados de las sociedad no podrán representar acciones o cuotas de terceros en la reunión de socios ni votar por balances y cuentas de fin de ejercicio (artículo 185); en la S.A. o S.C.A. nadie podrá ejercer como directivo en más de cinco juntas directivas (artículo 202); los administradores no pueden negociar acciones de la sociedad sin autorización previa (artículo 404); las juntas directivas no pueden estar conformadas por personas que tengan entre sí parentesco o vínculo matrimonial o marital, salvo en las sociedades de familia (artículo 435).

Estas supresiones normativas son desarrollo del principio general del derecho incorporado en el artículo 83 de la Constitución Política de Colombia y complementado por el artículo 871 del C.Co., por el cual los contratos deben de celebrarse y ejecutarse con buena fe, que permite para las S.A.S. que, sus administradores tengan un mayor margen de libertad en el ejercicio de sus funciones, donde deben obrar con la diligencia de buenos hombres de negocios de acuerdo con el artículo 23 de la Ley 222 , y que las decisiones y operaciones realizadas en la sociedad gocen de seguridad jurídica. Levantar estas restricciones en una S.A.S. tiene una razonable connotación, porque conociendo la realidad de las operaciones de la empresa, el administrador puede proponer a los socios un reparto de utilidades diferentes a las con- templadas, incluso, no distribución de estas, salvo en caso de acciones con dividendo fijo, por ejemplo, al pensar en un plan de expansión o de inversión. Y si los accionistas aprueban, de manera abusiva y como ilustración, el no reparto de utilidades, los minoritarios podrán demandar por tal abuso de mayoría con base en el artículo 43 de la Ley 1258 de 2008.

Igualmente, resultaría absurdo que, en una sociedad de familia, quien tenga funciones de administrador no pueda representar las acciones de su hijo menor de edad o de parientes que no estén en el lugar previsto para la reunión, por lo que el accionista deba asumir gastos de representación, pagando honorarios a un abogado para tal fin. Además, respecto de la junta directiva, en caso de que los accionistas la consideren útil para su compañía, quienes la conformen podrán tener relación de parentesco entre sí, aun cuando no se trate de una sociedad de familia, premiando la capacidad de administración de sus integrantes e imagen de confianza respecto de los accionistas, indistintamente del vínculo que exista entre los participantes del órgano.

Tal como ocurre con la junta directiva, el revisor fiscal en su calidad de representante de los accionistas al ejercer funciones de control y vigilancia de la administración de la sociedad no será una figura obligatoria en una S.A.S. en la medida que se pretende reducir costos operacionales para las sociedades cerradas. Ello es así a menos que los socios la estipulen como tal en sus estatutos o que la sociedad tenga a 31 de diciembre del año inmediatamente anterior, activos brutos iguales o superiores a 5.000 S.M.L.M.V. y/o ingresos brutos durante el año anterior por más de 3.000 S.M.M.L.V., según lo ordenado en el parágrafo segundo del artículo 13 de la Ley 43 de 1990. En los demás casos, de conformidad con el Decreto 2020 de 2009, las certificaciones y los dictámenes que deban ser emitidos por el revisor fiscal, podrán ser expedidos por un contador público independiente.

Dicha norma revalida el carácter flexible de la S.A.S. y su propósito de reducir los costos de su funcionamiento, principalmente, cuando se trata de 
sociedades de pequeñas dimensiones, cuyos montos de activos y de ingresos son pocos. Tampoco tendría utilidad la figura del revisor fiscal en una sociedad cerrada, cuando existe concentración de capital y son los mismos accionistas quienes ejercen la administración, además, es paradójico pensar que el revisor fiscal ejerce una función de control delegada por los socios, cuando ellos mismos son quienes eligen a los órganos de administración y ocupan los mismos cargos o ejercen este tipo de funciones.

Disolución, liquidación y exclusión en la S.A.S.

Ahora bien, de tratarse del fin de la S.A.S., la ley dispone unas causales para su disolución y liquidación, a saber: el vencimiento del término de duración previsto en los estatutos, si es que este no es indefinido, la imposibilidad de desarrollar el objeto social, iniciación del trámite de liquidación judicial por voluntad de la asamblea de accionistas o por orden de autoridad competente, por pérdidas que reduzcan el patrimonio neto de la sociedad por debajo del 50\% del capital suscrito; además, las partes podrán estipular libremente las causales que consideren para tal fin en los estatutos. Una vez reconocida la causal por la asamblea, la sociedad contará con un término de hasta dieciocho meses para adoptar las medidas necesarias para enervarlas y continuar con su funcionamiento, de lo contrario, el procedimiento liquidatario se realizará conforme a lo establecido para la Ltda.

Por ejemplo, cuando en una S.A.S. constituida únicamente por dos hermanos, se establezca que por la muerte de alguno de ellos, matrimonio o divorcio, la sociedad se disolverá, evitando así por la muerte o divorcio de alguno de los accionistas, en donde sus herederos por un proceso de sucesión o excónyuge por un trámite de liquidación de la sociedad conyugal, se hagan dueños de las acciones sin conocer del objeto social y tomen postura en la administración de la empresa.

El artículo 39 de la Ley 1258, respecto de la exclusión de accionistas, es una verdadera expresión de la libertad contractual en la S.A.S. respecto de las formas asociativas del C.Co. cuyas causales de exclusión son restrictivas y previstas por el legislador. Así, por ejemplo, el artículo 125 del C.Co. dispone de manera genérica para las sociedades reguladas en este estatuto que, cuando un socio no cumpla su deber de hacer su aporte en la forma dispuesta en los estatutos y en la regulación para cada tipo societario, la sociedad podrá elegir entre excluir al socio deudor, reducir su aporte hasta lo efectivamente entregado o hasta lo dispuesto a entregar o hacer efectiva la entrega del aporte.

Particularmente, el C.Co. establece otras causales de exclusión para cada tipo societario: en las sociedades colectivas, el inciso segundo del artículo 297 dispone que se da lugar a la exclusión del socio cuando éste haya explotado por cuenta propia o ajena, directa o por interpuesta persona, la misma clase de negocios que desarrolle la sociedad o que forme parte de sociedad por cuotas o partes de interés intervenido en su administración y en compañías por acciones que exploten el mismo objeto social; el artículo 298 también permite la exclusión cuando un socio retire cualquier bien de la sociedad o utilice la firma de ésta en negocios ajenos. Dándose lugar a la causal, el socio perderá el monto de su aporte y deberá indemnizar a la sociedad por los perjuicios acreditados (Superintendencia de Sociedades, 2018). Por disposición del artículo 341 y 352 del C.Co., las causales de exclusión de la sociedad colectiva también serán aplicables a los socios gestores en las sociedades en comandita (Superintendencia de Sociedades, 2013).

Respecto de la Ltda., el legislador ha estipulado en el artículo 365 que, cuando no se logre perfeccionar el trámite de cesión de cuotas la junta podrá excluir al socio interesado en ceder. (Superintendencia de Sociedades , 2016). Ahora bien, los socios también podrán establecer dentro de los estatutos que las causales de exclusión previstas en la sociedad colectiva sean aplicables a la Ltda. En cuanto a las S.A., por su naturaleza jurídica, la ley no consagra causales de exclusión y tampoco se considera viable 
pactar en los estatutos causales para tal fin (Superintendencia de Sociedades, 2018).

En suma, el tipo societario de la S.A.S. permite que sus accionistas dispongan de causales de exclusión y de un procedimiento para el mismo, que deben estar expresamente consagrados en los estatutos para su aplicación, como manifestación de la libertad de asociación que, de configurarse, mediante la aprobación de la mayoría de las acciones asistentes a la asamblea, sin contar al socio sobre quien se debate, se dé lugar al reembolso de su aporte (Superintendencia de Sociedades, 2011). Proponer causales de exclusión es una herramienta útil cuando se busca mantener como accionistas a miembros de una familia o a personas cercanas con las cuales existe una gran confianza, evitando el ingreso de terceros sin autorización de los socios o en casos de arribo de cierta edad de algún asociado; también cuando se busca prevenir actos de socios en contra de la explotación del objeto social de la compañía, como los actos que violen la reserva comercial, información privilegiada, actos de competencia desleal, conflictos de intereses y el servir como garantes con acciones.

Proponer causales de exclusión también es ventajoso cuando existan grupos empresariales y, en las sociedades que le conforman existan accionistas minoritarios que se opongan a la gestión de la administración y a la consecución de los fines del grupo; siendo excluidos, no habría incertidumbre respecto de las transacciones intragrupo al no existir demandas contra la sociedad alegando vulneración de los derechos e intereses de los minoritarios. Sobre este asunto también se ha afirmado y con toda razón que:

"Una estructura de capital sin inversionistas externos también eximirá a la sociedad de cumplir con ciertas formalidades como, por ejemplo, las de celebrar asambleas presenciales o disponer hospitalidades para el ejercicio del derecho de inspección. Más importante aún, con la desaparición de la minoría pierde vigor la amenaza de demandas de índole societario, incluida la temible ineficacia de decisiones asamblearias" (Mendoza, 2018, p.1).
Reorganizaciones y reformas estatutarias en la S.A.S.

Continuando con el análisis de la Ley 1258, de manera supletiva, la ley dispone en el artículo 32 que, en caso de enajenación global de activos, es decir, activos y pasivos que representen más de la mitad del patrimonio líquido de la sociedad, se requiere de la aprobación de la mayoría de las acciones presentes en la asamblea, facultando la solicitud de reembolso del aporte si es que el acto jurídico implica para el socio una desmejora patrimonial. Este tipo de reorganización empresarial no fue considerada para las otras formas societarias, acarreando una gran ventaja de las S.A.S. sobre las demás, ya que estas últimas deberán de realizar el procedimiento ordinario para la cesión.

En la S.A.S. este procedimiento estará sometido a la decisión de los administradores según sus facultades, y no de la reunión de los accionistas, por lo cual el asociado que se vea afectado no podrá ejercer el derecho de retiro. A juicio de la Superintendencia de Sociedades con ocasión a esta operación en la S.A.S. "la sociedad adquirente consolida su patrimonio con el de la sociedad vendedora, la que subsiste como inversionista con un único activo representado en las acciones que reciba como pago (Superintendencia de Sociedades, 2015), sin embargo, nada impide para que el cesionario sea una persona natural o un ente no societario que pague con bienes diferentes a dinero o acciones, o que el objeto de enajenación sea únicamente pasivos, por lo cual no habría necesidad de pagar por ellos (Sanín Gómez, 2018).

Para las S.A.S. también se estipuló la llamada fusión abreviada, es decir, cuando una sociedad controle más del $90 \%$ de acciones de una S.A.S., "la toma de la decisión no corresponde a la asamblea de accionistas, sino a los administradores de la sociedad, haciendo de esta manera más expedito el trámite de la fusión (Velásquez Restrepo, 2017, pág. 31), trasladando esta decisión de los accionistas a la administración, pero manteniendo el ejercicio del derecho de retiro. Dicha norma solamente es aplicable cuan- 
do la sociedad subordinada, la que es objeto de absorción es S.A.S., independientemente de la forma societaria de la compañía matriz, quien continuará con su estructura jurídica. Eso implica que una sociedad no S.A.S. que no haya podido transformarse en este último tipo societario por no contar con la unanimidad no podrá fusionarse de forma expedita y eficiente con su matriz y deberá seguir el procedimiento regular establecido en el C.Co.

Como se observa, la Ley 1258 se destaca por contener disposiciones en su mayoría supletivas, las cuales amplían el margen de libertad de estipulación de cláusulas estatutarias lícitas que tienen los socios al formar parte de una S.A.S.; sin embargo existen dos normas de carácter imperativo, que corresponde a los artículos 31 y 41. Del análisis del artículo 31 se exige la unanimidad para la llevará cabo cualquier proceso de transformación, fusión o escisión con relación a una S.A.S., respecto del artículo 41, se tiene que para incluir o modificar los dispuesto en los estatutos concerniente a la restricción de negociación de acciones, autorización de transferencia de acciones, exclusión de accionistas y resolución de conflictos societarios, y para la aprobación de procesos de transformación, fusión y escisión, la unanimidad de todos los accionistas. Estas disposiciones pretenden garantizar la iniciativa privada; en palabras de su autor, la norma tiene razón de ser ya que "radica esencialmente en el carácter estrictamente voluntario de la vinculación de sus accionistas" y por "la mayor exposición de riesgo al que podrían quedar sujetos los asociados que no han tenido la oportunidad de estipular las cláusulas que han de regir las relaciones intrasocietarias" (Reyes Villamizar, 2018, p. 20;282), aplicables en el momento de la constitución, cuando ingresa un nuevo accionista adhiriéndose a los estatutos, o cuando se da un proceso de transformación a S.A.S. Esta norma del artículo 41 puede resultar ser idónea porque permite mantener el control de la sociedad, sobre todos cuando se trate de sociedades cerradas, en particular sobre el ingreso de nuevos accionistas; en otro sentido, respecto de la figura de los socios minoritarios, el incluir o modificar cláusulas de exclusión o cláusulas compromisorias repre- sentaría un escenario inconveniente para ellos, toda vez que pueden ser objeto de su aplicación por parte de los mayoritarios y representa cargas para iniciar procesos judiciales en contra de la sociedad.

Por todo lo anteriormente expuesto, se demuestra un mayor grado de margen de libertad contractual para la estipulación del contenido de los estatutos en virtud de las normas en su mayoría dispositivas, en especial, sobre la conformación del capital, y de la simplificación de los procesos de creación, administración y supresión de las sociedades (Jaramillo Marín, 2014); por estas mismas razones se puede entender la prohibición de que la S.A.S. pueda inscribirse, cotizar y negociar sus acciones en el Registro Nacional de Valores y Emisores. Al respecto se ha dicho:

En verdad, la negociación de valores en bolsa justifica y da lugar a la imposición de múltiples regulaciones orientadas a proteger a los inversionistas dispersos en el mercado. Si se permitiera la inscripción en bolsa de la S.A.S., ello se haría, seguramente, en detrimento de la amplia libertad contractual que la caracteriza y que constituye una de las facetas más valiosas. Indudablemente, el legislador o regulador bursátil estaría inclinado a imponer severas cortapisas a dicha libertad de estipulación, a fin de proteger a los accionistas y tenedores de valores. (Reyes Villamizar, 2018, p. 361, 362).

A lo largo de este apartado se ha identificado el desarrollo de la autonomía privada de la voluntad en la S.A.S., características que evidencian una estructura maleable, en contraste con las formas societarias que le anteceden que suelen ser menos eficientes y adecuadas para la mayoría de negocios. Dicha virtud es conocida y aplicada por los nuevos inversionistas, quienes han acogido, en su gran mayoría, a la S.A.S. como modelo de negocio en las sociedades que se han constituido a partir de la promulgación de la Ley 1258 de 2008, evidenciando que la S.A.S., por su diseño normativo, es el mejor tipo societario en Colombia actualmente. 


\section{Conclusiones}

Sin duda alguna la S.A.S. es Colombia puede catalogarse como el modelo societario más eficiente para que los comerciantes desarrollen su empresa, no es en vano el número de comerciante que han adoptado su modelo mediante creación a partir del 5 de diciembre de 2008 y la cantidad de sociedades que habiéndose constituido inicialmente bajos los modelos societarios del C.Co. se han transformado a S.A.S.; situación que ha catapultado a la Ley 1258 de 2008 como ley modelo de S.A.S. para la O.E.A.

Esa eficiencia que pregona la S.A.S. se da por el mayor margen de acción de la libertad contractual, al proponer normas supletivas, las cuales podrán adoptar o no los accionistas, de tal manera que éstos definirán las reglas que le apliquen a sus compañías de acuerdo con sus necesidades e intereses, junto con la supresión de algunos requisitos ex ante y normas prohibitivas propias de las figuras societarias antiguas.

Como bien se ha dicho, el derecho societario tiende a la modernización de su contenido con el fin de hacerse más idóneo y ágil para las nuevas realidades sociales, siendo una herramienta que de la mano de incentivos tributarios y de crédito faciliten la actividad mercantil, la formalización empresarial y sostenimiento de la sociedad comercial.

Pese a que el objetivo se ha cumplido con la Ley 1258 de 2008, la tarea continúa y la necesidad no se ha satisfecho; el derecho se encuentra en una constante acción de mejora. Así entonces, valdría la pena considerar suprimir o modificar normas relativas de la libertad contractual, en particular, aquella que define la unanimidad como requisito para la transformación de una sociedad del C.Co. a S.A.S. o viceversa, o para la fusión o escisión para cuando resulte beneficiara una S.A.S., regla que impide que aquellos empresarios que constituyeron su sociedad antes del 5 de diciembre de 2008 y que por cualquier motivo no han podido transformarse a S.AS. puedan hacerlo mediante la aprobación de sus socios mayoritarios, y así, puedan gozar de los be- neficios de la S.A.S. que le han sido esquivos por más de una década.

Incluso, sería posible reevaluar aquellas normas que determinan qué tipo societario se debe asumir según el objeto social que se desarrolla, como por ejemplo, el Decreto 356 de 1994 que establece que quienes presten servicios de vigilancia y seguridad deben ser Ltda., situación que podría disminuir el número de sociedades disueltas y liquidadas, atrayendo la inversión y salvación de empresas consolidadas. 


\section{Referencias}

Arrubla Paucar, J. A. (1997). Contratos Mercantiles. Tomo I (Octava ed.). Medellín: Biblioteca Jurídica Diké.

Betancourt Ramírez, J. B., Gómez Betancourt, G., López Vergara, M. P., Pamplona Beltrán, F., \& Beltrán Ruget, C. (2013). Ventajas y desventajas de la Sociedad Por Acciones Simplificada para la empresa familiar en Colombia. Estudio Exploratorio. Estudios Gerenciales, 29.213-221.

Confederación de Cámaras de Comercio. (2007). Número de sociedades por organización jurídica en 2007. Bogotá D.C.

Confederación de Cámaras de Comercio. (2019). Número de sociedades por organización jurídica a 9 de agosto de 2019, en respuesta a derechodepetición radicadoel 8 de agosto de 2019. BogotáD.C.

Congreso de la República. (13 de diciembre de 1990). Por la cual se adiciona la Ley 145 de 1960, reglamentaria de la profesión de Contador Público y se dictan otras disposiciones. (Ley 43 de 1990). DO: 39602

Congreso dela República. (13 de Mayo de 2008). Informe de ponencia para primer debate al proyecto de ley No. 241 de 2008 Cámara, 039 de Senado. Gaceta del Congreso No. 248. Bogotá D.C.

Congreso de la República. (20 de diciembre de 1995). Por la cual se modifica el Libro II del Código de Comercio, se expide un nuevo régimen de procesos concursales y se dictan otras disposiciones. Ley 222 de 1995. DO: 42.156

Congreso de la República. (26 de enero de 2006). De fomento a la cultura del emprendimiento. Ley 1014 de 2006. DO: 46.164

Congreso de la República. (27 de diciembre de 2006). Por la cual se establece el Régimen de Insolvencia Empresarial en la República de Colombia y se dictan otras disposiciones. Ley 1116 de 2006. DO: 46.494

Congreso de la República. (5 de diciembre de 2008). Por medio de la cual se crea la sociedad por acciones simplificada. Ley $1258 \mathrm{de}$ 2008. DO: 47.194

Corte Constitucional. Sala Plena. (19 de febrero de 2014). Sentencia
C-090 de 2014. M.P. Mauricio González Cuervo.

Espinosa Quintero, L. (2011). El proceso de flexibilización del régimen societario colombiano: Una visión desde la evolución de las figuras empresariales. (U. S. Arboleda, Ed.) Cuadernos de la Maestría en Derecho(1), 245-284.

Frontera, J. C. (2007). La descodificación como síntoma de la historicidad del derecho. Revista electrónica del Instituto de Investigaciones "Ambrosio L. Gioja"(1), 224-231.

Gaviria Gutiérrez, E. (2004). Apuntes sobre el derecho de las sociedades (Primera ed.). Medellín: Señal Editorial.

Granados Aristizábal, J. I. (2013). Las declaraciones publicitarias y la integración de las obligaciones que de ellas emanan al contenido del contrato con el consumidor. E Mercatoria, XII(1), 1-48.

Hinestrosa, F. (1969). Derecho Civil, Obligaciones. Bogotá D.C.: Universidad Externado de Colombia.

Jaramillo Marín, R. S. (2014). Diferentes miradas sobre la Sociedad por Acciones Simplificada (SAS. Tras un nuevo conocimiento. Revista Saber, Ciencia y Libertad, IX (2), 71-88.

Macías Reyes, V. (2018). Análisis crítico a la legislación de las sociedades por acciones simplificadas. Cali. Obtenido de http://vitela. javerianacali.edu.co/bitstream/handle/11522/10388/Analisis_ critico_legislacion.pdf?sequence $=1 \&$ sisAllowed $=y$

Mendoza, J. M. (11 de abril de 2018). Exclusión forzosa de accionistas minoritarios. Ámbito Jurídico. Obtenido de https://www.ambitojuridico.com/noticias/columnistaimpreso/sociedades-y-economia-solidaria/exclusion-forzosa-de-accionistas

Mendoza, J. M. (4 de julio de 2019). La comandita: R.I.P. Ámbito Jurídico. Obtenido de https://www.ambitojuridico.com/noticias/ columnista-impreso/sociedades-y-economiasolidaria/la-comandita-r-i-p

Peña Nossa, L. (2017). De las sociedades comerciales (Octava ed.). Bogotá D.C.: Ecoe Ediciones. Obtenido de https://books.google. com.co/books?id=DK9JDwAAQBAJ\&lpg=PP1\&hl=es\&p$\mathrm{g}=\mathrm{PT} 49 \# \mathrm{v}=$ onepage $\& \mathrm{q} \& \mathrm{f}=$ false 
Presidente de la República. (2 de junio de 2009). Por medio del cual se reglamenta el artículo 28 de la Ley 1258 de 2008. Decreto 2020 de 2009.

Presidente de la República. (27 de marzo de 1971). Por el cual se expide el Código de Comercio. Decreto Ley 410 de 1971.

Presidente de la República. (30 de marzo de 1989). Por el cual se expide el Estatuto Tributario de los Impuestos Administrados por la Dirección General de Impuestos Nacionales. Decreto 624 de 1989.

Presidente de la República. (5 de agosto de 1950). Por el cual se decreta el Código Sustantivo del Trabajo. Decreto 2663 de 1950.

Reyes Villamizar, F. (2018). SAS Sociedad por Acciones Simplificada (Cuarta ed.). Bogotá D.C.: Legis.

Sanín Gómez, J. E. (9 de junio de 2018). La enajenación global de activos. El Mundo. Obtenido de: https://www.elmundo.com/noticia/La-enajenacion-global-deactivos/372007

Sayas Contreras, R., \& Medina Arteta, R. (2016). Caracterización de las funciones jurisdiccionales de la Superintendencia de Industriay Comercio, en el marco de la protección de los derechos del consumidor.Advocatus, 14(27), 117-131

Superintendencia de Sociedades. (2000). Oficio 220-46127. Superintendencia de Sociedades, Bogotá D.C.

Superintendencia de Sociedades. (2009). Oficio 220-121211. Superintendencia de Sociedades, Bogotá D.C.

Superintendencia de Sociedades. (2011). Oficio 220-113870. Superintendencia de Sociedades, Bogotá D.C.

Superintendencia de Sociedades. (2013). Oficio 220-043848. Superintendencia de Sociedades, Bogotá D.C.

112 Superintendencia de Sociedades. (2015). Bogotá D.C. Sentencia de Edgar Orlando Corredor vs. Induesa Pinilla \& Pinilla S. en C. y Juan Manuel Pinilla, Radicado 2015-01-276188. Superintendente Delegado para Procedimientos Mercantiles.

Superintendencia deSociedades. (2016). Oficio 220-195706.Superin- tendencia de Sociedades, Bogotá D.C.

Superintendencia de Sociedades. (2018). Oficio 220-042318. Superintendencia de Sociedades, Bogotá D.C.

Superintendencia de Sociedades. (2018). Oficio 220-161575. Superintendencia de Sociedades, Bogotá D.C.

Veiga-Copo, A. B. (2011). El régimen jurídico de las acciones en la SAS (I). Vniversitas (123), 373- 410.

Velásquez Restrepo, C. A. (7 de febrero de 2017). La Sociedad por Acciones Simplificadas. Recuperado de: http:/www.carlosavelasquez.com/wpcontent/uploads/2018/04/sociedad-por-acciones-simplificada.pdf

Villa Uribe, D. (2015). Persona jurídica y la responsabilidad limitada de las sociedades comerciales colombianas (Tesis para la maestría, Universidad Pontificia Bolivariana, Medellín, Colombia). Obtenido de https://repository.upb.edu.co/bitstream/handle/20.500.11912/2777/Art\%C3\%ADculo\%20 Publicable_MD_ David\%20Villa\%20Uribe.pdf?sequence $=1 \&$ isAllowed $=$ y

2020, Vol. 13(26) 93-112. (CThe Author(s) 2020

Reprints and permission: www.americana.edu.co http://publicaciones.americana.edu.co/index.php/pensamientoamericano/index 